\title{
OPTIMASI KERJA PELUNCUR ROKET PADA ROBOT RODA RANTAI UNTUK MENENTUKAN KETEPATAN SUDUT TEMBAK
}

\author{
Joko Lasmono', Anggraini Puspita Sari', Mayor Arh. Eko Kuncoro², Irfan Mujahidin' \\ ${ }^{1}$ Jurusan TeknikElektro UNMER Malang \\ 2 Departemen Optik dan Hidrolik Lemjiantek TNI-AD \\ Email : lesmono997@gmail.com
}

\begin{abstract}
Abstrak
Pada perkembangan teknologi saat ini banyak dikembangkan jenis robot dengan kemampuan yang menarik adalah robot dengan berbagai macam model dan bentuk karakteristiknya. Pada saat ini peluncur roket masih dikendalikan oleh manusia yang memanfaatkan teknologi dengan menggunakan pc dan motor servo sebagai alat pengendali untuk menentukan ketepatan pada sudut tembaknya, dalam merancang robot ini dibutuhkan kelengkapan komponennya agar robot dapat bekerja secara otomatis sesuai dengan masukan yang diberikan, robot peluncur roket dikendalkan secara otomatis dengan komunikasi dari pc kemudian perintah tersebut diteruskan ke mikrokontroler menggunakan kabel USB TTL kemudian dikirim ke rangkaian Xbee-pro pengirim kemudian dipancarkan dan di terima oleh Xbee-pro penerima kemudian di transmisikan ke mikrokontroler dan diolah menuju ke sistem kendalinya yang berupa motor servo dan relay sebagai komponen pada bagian penembakan peluncur roketnya. Berdasarkan hasil pengujian robot telah mampu mengarahkan peluncur roket tepat pada sudut yang sudah ditentukan dan telah mampu melakukan aksi penembakan pada tiap peluncurnya dengan tingkat keberhasilan mencapai $80 \%$.
\end{abstract}

Kata Kunci : Peluncur Roket, Optimasi, Motor Servo

\section{Pendahuluan}

Dalam era perkembangan teknologi saat ini kebutuhan Alutsista dan peralatan untuk TNI semakin berkembang. Kebutuhan tersebut dapat dipenuhi melalui kemampuan produksi di dalam negeri. Faktor yang berperan besar dalam pengembangan teknologi pertahanan dan keamanan adalah kebutuhan dan kemampuan penguasaan teknologi Alutsista dan peralatan TNI khususnya TNI AD beserta sarana-prasarana pendukungnya. Faktor tersebut merupakan landasan dalam perumusan arah, prioritas, serta kebijakan pengembangan dan penguasaan teknologi pertahanan dan keamanan khususnya dalam bidang persenjataan. Pada perkembangan teknologi saat ini, semua peralatan sudah menggunakan teknologi yang modern terutama pada sistem persenjataan yang ada di lingkungan TNI[1]. Perkembangan ilmu pengetahuan dan teknologi di beberapa negara maju telah menciptakan robot sebagai sarana untuk membantu meningkatkan profesionalisme prajuritnya seperti "Robot Penjinak Bom MOROLIPI [1] yang digunakan oleh pasukan Jihandak Polri untuk menjinakkan bahan peledak, "Aplikasi Model Mobile Manipulator Pada Robot Penjinak Bom" yang digunakan untuk menjinakan bom dengan beban $0,5 \mathrm{~kg}[2]$.

Seiring dengan perkembangan teknologi terutama di bidang elektronika, sebuah robot dalam dunia militer sangat membantu dalam mengatasi berbagai situasi dan kondisi yang berbahaya, baik saat di medan perang maupun di medan - medan yang sulit di jangkau oleh manusia[3]. Di Indonesia sangat membutuhkan sebuah teknologi robot yang berguna untuk membantu kinerja personel TNI AD, dalam rangka menjaga keamanan dan keutuhan negara Indonesia dari ancaman pihak negara asing.

\section{Metode Penelitian}

Metode penelitian yang bertujuan untuk merancang, meneliti dan mengembangkan suatu rangkaian dasar dengan mempertimbangkan berbagai macam aspek, baik dari segi mutu, 
anggaran dan kegunaan dari sistem pengendali dan pengontrol alat yang penulis buat bagi TNIAD dalam tugas operasi pertempuran[4][5].

\subsection{Variabel Penelitian}

Variabel penelitian yang digunakan pada penelitian ini adalah parameter yang ditentukan sebagai indikator perbandingan.

\subsection{Skema Arsitektur Perancangan}

Banyak peneliti yang membahas dan berusaha menemukan solusi terbaik perkembangan teknologi balancing robot. Beberapa metodologi sudah diterapkan pada penelitian sebelumnya. Penelitian ini dilakukan dengan membuat alat optimasi kerja peluncur roket untuk menentukan ketepatan pada sudut tembak[6]. Dengan adanya metodologi ini membantu proses sistem kerja alat secara keseluruhan.

\subsubsection{Diagram Blok}

Dalam perencanaan pembuatan alat, keseluruhan sistem digambarkan dalam blok diagram alat yang ditunjukkan pada Gambar 3.1.

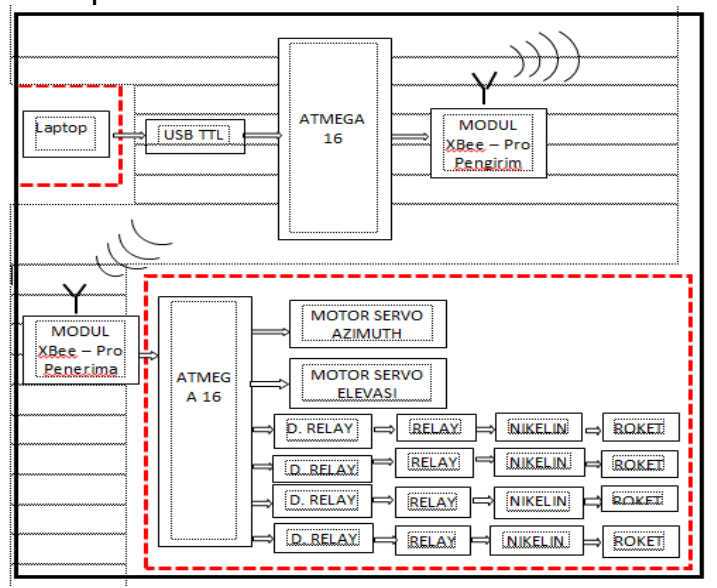

Gambar 2.1 Blok Diagram

Berdasarkan gambar blok diagram yang ditunjukkan dalam Gambar 3.1 dapat diketahui sistem kerja dari alat yaitu sebagai berikut :

1. Xbee-pro. Rangkaian ini berkerja sebagai penerima data hasil pengiriman yang dipancarkan melalui modul Xbee-pro pengirim, data tersebut di terima kemudian di kirim menuju mikrokontroler ATMega 16.

2. Data yang masuk pada mikrokontroler ATMega 16 diolah dan dikirim kembali menuju motor servo untuk menggerakan motor elevasi maupun azimuth

3. Data yang masuk mikrokontroler Atmega 16 diolah dan di kirim ke driver relay, kemudian menuju nikelin untuk melakukan penembakan pada roket, tergantung dari data yang di kirim oleh ATMega 16.

\subsection{Perencanaan Sistem}

Perencanaan pembuatan alat optimasi kerja peluncur roket pada robot roda rantai untuk menentukan ketepatan sudut tembak ini terdiri dari perancangan perangkat keras dan perancangan perangkat lunak[7]. Perancangan hardware meliputi perancangan dan perakitan desain motor servo, perancangan dan perakitan pengendali peluncur roket, perakitan dan perancangan penembakan. Sedangkan perancangan software meliputi perancangan list program yang akan dimuat pada PC untuk mengeksekusi dan menjalankan perintah program saat PC menerima masukan.

\subsubsection{Perancangan Mekanik}

Mekanik yang direncanakan adalah desain dari peluncur roket agar dapat digunakan dan ditempatkan di atas robot roda rantai. Pada posisi berdiri vertikal pada saat pengujian berlangsung. Alat ini berbentuk persegi dengan panjang $28,5 \mathrm{~cm}$, lebar $10 \mathrm{~cm}$, dan tinggi 22,5 $\mathrm{cm}$, di bentuk dengan menggunakan besi pipa berbentuk persegi yang dirangkai dengan cara di las[8]. Di tempat peluncur roket tersebut berdiri vertikal diberi motor servo agar pada saat pengujian peluncur roket tersebut dapat bergerak ke atas, bawah, kanan maupun ke kiri. Pada bagian samping alat terdapat kotak yang berisi rangkaian elektronika yang terdiri dari mikrokontroler, dan baterai sebagai daya untuk menyalakan alat tersebut[9]. Perangkat elektronika berfungsi untuk mengolah data yang kemudian akan mengerakkan peluncur roket. Gambar 3.4 menunjukkan perancangan peluncur roket. 


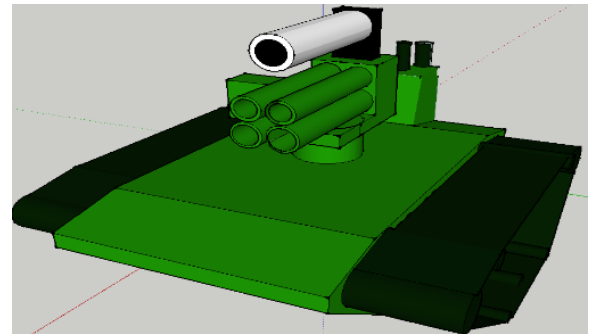

Gambar 2.2 Perancangan mekanik peluncur roket

\subsubsection{Perancangan Perangkat Mikrokontroler Dan Motor Servo}

Rangkaian minimum sistem adalah rangkaian minimal untuk dapat mengaktifkan chip mikrokontroler sehingga dapat bekerja (running). Rangkaian minimum sistem merupakan rangkaian elektronika yang terdiri dari komponen dasar yang dibutuhkan oleh sebuah mikrokontroler untuk dapat bekerja dan berfungsi dengan baik membaca dan mengeksekusi setiap perintah program yang diinputkan ke mikrokontroler tersebut. Rangkaian minimum sistem mikrokontroler Atmega 16 dan motor servo seperti pada Gambar 3.5[10].

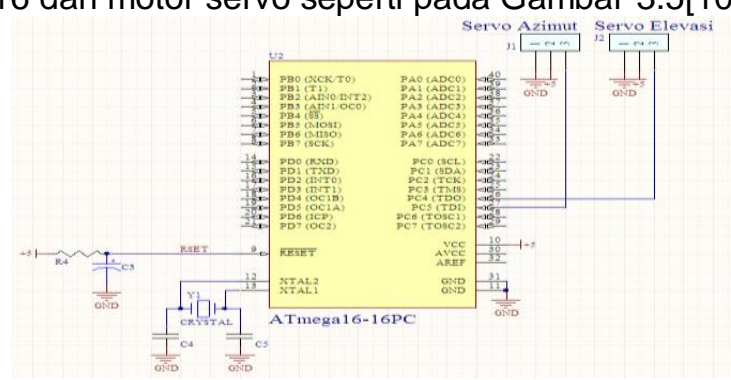

Gambar 2.3 Perencanaan Rangkaian Mikrokontroler dan Motor Servo

\subsubsection{Perancangan Pengendali Peluncur Roket}

Rangkaian minimum sistem adalah rangkaian minimal untuk dapat mengaktifkan chip mikrokontroler sehingga dapat bekerja (running). Rangkaian minimum sistem merupakan rangkaian elektronika yang terdiri dari komponen dasar yang dibutuhkan oleh sebuah mikrokontroler untuk dapat bekerja dan berfungsi dengan baik, membaca dan mengeksekusi setiap perintah program yang diinputkan ke mikrokontroler tersebut[11][12]. Rangkaian pengendali peluncur roket digunakan sebagai komponen agar peluncur roket tersebut dapat diaplikasikan, yang ditunjukkan pada Gambar 3.6.

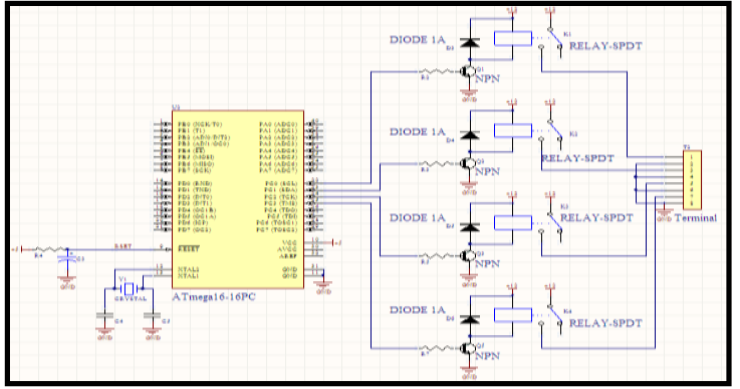

Gambar 2.3 Pengendali Roket

\begin{tabular}{|c|c|c|c|c|c|c|c|c|c|c|}
\hline \multirow[b]{2}{*}{ No } & \multirow{2}{*}{$\begin{array}{l}\text { Data } \\
\text { Pemro } \\
\text { gaman }\end{array}$} & \multicolumn{8}{|c|}{ Nyala LED } & \multirow{2}{*}{$\begin{array}{l}\text { Keter } \\
\text { angan }\end{array}$} \\
\hline & & 1 & 2 & 3 & 4 & 5 & 6 & 7 & 8 & \\
\hline 1 & $\begin{array}{l}\& B 000 \\
00000\end{array}$ & 0 & 0 & 0 & 0 & 0 & 0 & 0 & 0 & \\
\hline 2 & $\begin{array}{l}\& B 000 \\
00001\end{array}$ & 0 & 0 & 0 & 0 & 0 & 0 & 0 & 1 & $\begin{array}{l}1=\text { On } \\
0=\text { Off }\end{array}$ \\
\hline 3 & $\begin{array}{l}\& B 000 \\
00010\end{array}$ & 0 & 0 & 0 & 0 & 0 & 0 & 1 & 0 & \\
\hline 4 & $\begin{array}{l}\& B 000 \\
00100\end{array}$ & 0 & 0 & 0 & 0 & 0 & 1 & 0 & 0 & \\
\hline 5 & $\begin{array}{l}\& B 000 \\
01000\end{array}$ & 0 & 0 & 0 & 0 & 1 & 0 & 0 & 0 & \\
\hline 6 & $\begin{array}{l}\& B 000 \\
10000\end{array}$ & 0 & 0 & 0 & 1 & 0 & 0 & 0 & 0 & \\
\hline 7 & $\begin{array}{l}\& B 001 \\
00000\end{array}$ & 0 & 0 & 1 & 0 & 0 & 0 & 0 & 0 & \\
\hline 8 & $\begin{array}{l}\& B 010 \\
00000\end{array}$ & 0 & 1 & 0 & 0 & 0 & 0 & 0 & 0 & \\
\hline 9 & $\begin{array}{l}\& B 100 \\
00000\end{array}$ & 1 & 0 & 0 & 0 & 0 & 0 & 0 & 0 & \\
\hline
\end{tabular}




\section{HASIL DAN ANALISIS}

Setelah perancangan alat selesai, maka dilakukan pengujian untuk mengetahui apakah alat yang telah dirancang dan dibuat berjalan seperti yang telah direncanakan. Pengujian dilakukan untuk membandingkan hasil perancangan teoritis dengan hasil percobaan atau pengujian[13]. Dari hasil pengujian dapat diketahui apakah alat telah bekerja sesuai dengan spesifikasi yang diinginkan.

\subsection{Hasil Pengujian Minimum Sistem Atmega16}

Pengujian minimum sistem Atmega16 dilakukan untuk mengetahui cara kerja Minimum Sistem Mikrokontroler yang akan digunakan dapat bekerja dengan baik atau belum. Proses pengujian dilakukan dengan memasukkan program yang dibuat dengan menggunakan bahasa pemrograman Bascom (Basic Compiler). Analisis hasil pengujian menunjukkan bahwa Port $C$ sebagai output pada mikrokontroler dapat berfungsi dengan baik.

Dari Hasil pengujian dapat disimpulkan bahwa LED akan off (mati) jika Port $C$ bernilai low(0) dan LED akan on (hidup) apabila Port $C$ bernilai high (1). Lampu LED juga akan bergerak ke kiri kemudian kembali ke kanan. Bedasarkan hasil pengujian dapat disimpulkan bahwa minimum sistem mikrokontroler Atmega16 dapat berfungsi dengan baik.

\subsection{Hasil Pengujian Relay}

Pada pengujian relay ini dilakukan dengan menguji satu persatu relay yang akan digunakan untuk mengaktifkan tembakan pada peluncur rioket. Dalam pengujian ini dilakukan mengunakan modul pada rangkaian relay dengan output menggunakan LED yang ditunjukkan pada Tabel 3.2.

Tabel 3.1 Hasil Pengujian Relay
\begin{tabular}{|c|c|c|c|c|}
\hline $\begin{array}{c}\text { Output } \\
\text { relay }\end{array}$ & \multicolumn{4}{|c|}{ Logika rangkaian MK } \\
\cline { 2 - 5 } & Port C.0 & $\begin{array}{c}\text { Port } \\
\text { C.1 }\end{array}$ & $\begin{array}{c}\text { Port } \\
\text { C.2 }\end{array}$ & $\begin{array}{c}\text { Port } \\
\text { C.3 }\end{array}$ \\
\hline $\begin{array}{c}\text { Roket } \\
\text { A }\end{array}$ & 1 & 0 & 0 & 0 \\
\hline $\begin{array}{c}\text { Roket } \\
\text { B }\end{array}$ & 0 & 1 & 0 & 0 \\
\hline $\begin{array}{c}\text { Roket } \\
\text { C }\end{array}$ & 0 & 0 & 1 & 0 \\
\hline $\begin{array}{c}\text { Roket } \\
\text { D }\end{array}$ & 0 & 0 & 0 & 1 \\
\hline
\end{tabular}

Dari Hasil pengujian yang ditunjukkan pada Tabel 4.2 dapat disimpulkan bahwa pengujian rangkaian relay berjalan dengan baik yang ditunjukkan dengan nyala pada LED indikator yang sesuai dengan logika yang diberikan MK, indikator untuk roket A menyala ketika diberikan logika "1" pada port C.0 dan logika "0" pada port C lainnya. Kemudian roket B menyala ketika diberikan logika "1" pada port C.1 dan logika "0" pada port C lainnya begitu juga roket C menyala ketika diberikan logika "1" pada port C.2 dan logika "0" pada port C lainnya. Dan roket D menyala ketika diberikan logika "1" pada port C.3 dan logika "0" pada port C lainnya.

\subsection{Hasil Pengujian Pulsa Dan Sudut Elevasi}

Dengan Pengujian motor servo untuk mengetahui sudut elevasi yang inputnya berasal dari pulsa yang dimasukkan. Dan membuat Tabel hasil pengujian sinyal motor servo elevasi yang ditunjukkan dalam Tabel 3.3.

Tabel 3.2 Pengujian pulsa dan sudut elevasi

\begin{tabular}{|c|c|c|c|c|}
\hline \multirow{2}{*}{ Pulsa } & \multicolumn{4}{|c|}{ Hasil Pengujian Pulsa Dan Sudut Elevasi } \\
\cline { 2 - 5 } & Uji 1 $\left(^{\circ}\right)$ & Uji 2 $\left(^{\circ}\right)$ & Uji 3 $\left(^{\circ}\right)$ & $\begin{array}{c}\text { Rata } \\
\text { Rata }\end{array}$ \\
\hline 500 & 0 & 0 & 0 & 0 \\
\hline 600 & 10 & 10,1 & 10,1 & 10.067 \\
\hline 700 & 20 & 20 & 20 & 20 \\
\hline 800 & 30 & 30 & 30 & 30 \\
\hline 900 & 40 & 40,2 & 40,1 & 40,1 \\
\hline 1000 & 50 & 50 & 50 & 50 \\
\hline 1100 & 60 & 60,1 & 60,1 & 60,067 \\
\hline
\end{tabular}




\begin{tabular}{|l|l|l|l|l|}
\hline 1200 & 70 & 70 & 70 & 70 \\
\hline
\end{tabular}

Dari hasil pengujian motor servo elevasi dengan pulsa yang dimasukan kemudian dibandingkan dengan tiga kali pengujian dan dapat diambil rata rata yang ditunjukan pada Tabel 4.3.

\subsection{Pengujian Pengukuran Sinyal PWM Pada Motor Servo Elevasi}

Dalam pengujian motor servo mendapatkan hasil pengukuran sinyal menggunakan oscilloscope. Sinyal Input dari mikrokontroler menuju motor servo dengan pulsa 500 dalam keadaan $0^{\circ}$ dengan Pengaturan oscilloscope menggunakan volt/div $=2 \mathrm{~V}$, time/div $=2 \mathrm{~ms}$

Tabel 3.4 Hasil pengujian waktu sinyal input pada motor servo elevasi

\begin{tabular}{|c|c|c|c|}
\hline Sudut $\left(^{\circ}\right)$ & \multicolumn{2}{|c|}{ Periode } & $\begin{array}{c}\mathrm{T}_{\text {total }} \\
\text { (ms) }\end{array}$ \\
\cline { 2 - 3 } & $\mathrm{T}_{\text {on }}(\mathrm{ms})$ & $\mathrm{T}_{\text {off }}(\mathrm{ms})$ & \\
\hline 0 & 0,4 & 16,4 & 16,8 \\
\hline 10 & 0,5 & 16,4 & 16,9 \\
\hline 20 & 0,6 & 16,4 & 17 \\
\hline 30 & 0,7 & 16,4 & 17,1 \\
\hline 40 & 0,8 & 16,4 & 17,2 \\
\hline 50 & 0,9 & 16,4 & 17,3 \\
\hline 60 & 1,0 & 16,4 & 17,4 \\
\hline 70 & 1,1 & 16,4 & 17,5 \\
\hline
\end{tabular}

Dari hasil pengujian pengukuran sinyal periode pada motor servo pada sudut elevasi dapat di peroleh hasil yang ditunjukkan pada Tabel 4.5.

\subsection{Hasil Pengujian Pulsa Dan Sudut Azimuth}

Tabel 3.5. Pengujian pulsa dan sudut azimuth

\begin{tabular}{|c|c|c|c|c|}
\hline \multirow{2}{*}{ Pulsa } & \multicolumn{4}{|c|}{ Hasil Pengujian Pulsa Dan Sudut Elevasi } \\
\cline { 2 - 5 } & Uji 1 $\left(^{\circ}\right)$ & Uji 2 $\left(^{\circ}\right)$ & Uji 3 $\left(^{\circ}\right)$ & $\begin{array}{c}\text { Rata } \\
\text { Rata }\end{array}$ \\
\hline 500 & 0 & 0 & 0 & 0 \\
\hline 600 & 10 & 10,1 & 10,1 & 10.067 \\
\hline 700 & 20 & 20 & 20 & 20 \\
\hline 800 & 30 & 30 & 30 & 30 \\
\hline 900 & 40 & 40,2 & 40,1 & 40,1 \\
\hline 1000 & 50 & 50 & 50 & 50 \\
\hline 1100 & 60 & 60,1 & 60,1 & 60,067 \\
\hline 1200 & 70 & 70 & 70 & 70 \\
\hline 1300 & 80 & 80 & 80 & 80 \\
\hline 1400 & 90 & 90 & 90 & 90 \\
\hline 1500 & 100 & 100 & 100 & 100 \\
\hline 1600 & 110 & 110,1 & 110,1 & 110,067 \\
\hline 1700 & 120 & 120,1 & 120,1 & 120,067 \\
\hline 1800 & 130 & 130 & 130 & 130 \\
\hline 1900 & 140 & 140,1 & 140,1 & 140,067 \\
\hline 2000 & 150 & 150 & 150 & 150 \\
\hline 2100 & 160 & 160,2 & 160,1 & 160,1 \\
\hline 2200 & 170 & 170 & 170 & 170 \\
\hline 2300 & 180 & 180 & 180 & 180 \\
\hline
\end{tabular}

Dari hasil pengujian motor servo azimuth dengan pulsa yang dimasukan kemudian dibandingkan dengan tiga kali pengujian dan dapat diambil rata rata yang ditunjukan pada Tabel 3.5.

\subsection{Pengujian Pengukuran Sinyal PWM Pada Motor Servo Azimuth}

Dalam pengujian motor servo mendapatkan hasil pengukuran sinyal menggunakan oscilloscope. Sinyal Input dari mikrokontroler menuju motor servo dengan pulsa 500 dalam keadaan $0^{\circ}$ dengan Pengaturan oscilloscope menggunakan volt/div $=2 \mathrm{~V}$, time $/ \mathrm{div}=2 \mathrm{~ms}$

Tabel 3.6. Hasil pengujian waktu sinyal input pada motor servo Azimuth

\begin{tabular}{|c|c|c|c|}
\hline \multirow[t]{2}{*}{ Sudut $\left({ }^{\circ}\right)$} & \multicolumn{2}{|c|}{ Periode } & \multirow[t]{2}{*}{$\mathrm{T}_{\text {total }}(\mathrm{ms})$} \\
\hline & $\mathrm{T}_{\text {on }}(\mathrm{ms})$ & $\mathrm{T}_{\text {off }}(\mathrm{ms})$ & \\
\hline 0 & 0,4 & 16,4 & 16,8 \\
\hline
\end{tabular}




\begin{tabular}{|c|c|c|c|}
\hline 10 & 0,5 & 16,4 & 16,9 \\
\hline 20 & 0,6 & 16,4 & 17 \\
\hline 30 & 0,7 & 16,4 & 17,1 \\
\hline 40 & 0,8 & 16,4 & 17,2 \\
\hline 50 & 0,9 & 16,4 & 17,3 \\
\hline 60 & 1,0 & 16,4 & 17,4 \\
\hline 70 & 1,1 & 16,4 & 17,5 \\
\hline 80 & 1,2 & 16,4 & 17,6 \\
\hline 90 & 1,3 & 16,4 & 17,7 \\
\hline 100 & 1,4 & 16,4 & 17,8 \\
\hline 110 & 1,5 & 16,4 & 17,9 \\
\hline 120 & 1,6 & 16,4 & 18 \\
\hline 130 & 1,7 & 16,4 & 18,1 \\
\hline 140 & 1,8 & 16,4 & 18,2 \\
\hline 150 & 1,9 & 16,4 & 18,3 \\
\hline 160 & 2,0 & 16,4 & 18,4 \\
\hline 170 & 2,1 & 16,4 & 18,5 \\
\hline 180 & 2,2 & 16,4 & 18,6 \\
\hline
\end{tabular}

Dari hasil pengujian pengukuran sinyal periode pada motor servo pada sudut azimuth dapat di peroleh hasil yang ditunjukkan pada Tabel 4.5.

\section{Kesimpulan}

Dari penelitian yang telah dilaksanakan, dapat disimpulkan bahwa:

1. Peluncur roket dapat bergerak dengan sudut azimuth dari $0^{\circ}-180^{\circ}$ dengan diberikan pulsa 500-2300 ms sehingga peluncur roket dapat bergerak sesuai dengan sudut yang diinginkan.

2. Peluncur roket dapat bergerak dengan sudut azimuth dari $0^{\circ}-70^{\circ}$ dengan diberikan pulsa 500-1200 ms sehingga peluncur roket dapat bergerak sesuai dengan sudut yang diinginkan.

3. Mengaktifkan penembakan senjata pada peluncur roket yang ada pada robot roda rantai agar penembakannya dapat bekerja dengan baik dengan adanya relay sebagai pemicu tembaknya.

\section{Daftar Pustaka}

[1] R. M. Murray, Z. Li, and S. Shankar Sastry, A mathematical introduction to robotic manipulation. 2017.

[2] D. Saputra, D. Cahyadi, and A. H. Krisdalaksana, "Sistem Otomasi Perpustakaan Dengan Menggunakan Radio Frequency Identification ( RFID )," Inform. Mulawarman J. IIm. IImu Komput., 2010.

[3] R. A. Brooks, "A Robust Layered Control System For A Mobile Robot," IEEE J. Robot. Autom., 1986.

[4] B. Arthayaa, A. Sadiyokob, and C. Wiejaya, "Pengembangan Algoritma Pengenalan Bentuk dan Arah Objek pada Sistem Omnidirectional Vision Sensor," J. Tek. Elektro, 2013.

[5] I. Mujahidin, R. Yuwono, and A. Mustofa, "Rancang Bangun Rectifier Antenna Mikrostrip Ufo Pada Frekuensi Ultra Wideband (UWB) Sebagai Pemanen Energi Elektromagnetik," J. Mhs. TEUB, vol. 3, no. 2, 2015.

[6] I. Oktariawan, Martinus, and Sugiyanto, "Pembuatan Sistem Otomasi Dispenser Menggunakan Mikrokontroler Arduino Mega 2560," J. FEMA, 2013.

[7] R. Yuwono, I. Mujahidin, A. Mustofa, and Aisah, "Rectifier using UFO microstrip antenna as electromagnetic energy harvester," Adv. Sci. Lett., 2015.

[8] A. N. Putri, "Penerapan Fuzzy Controller Untuk Pergerakan Player Pada Game Engine 3d Berbasis Agen Cerdas," J. Transform., 2017.

[9] I. Mujahidin, "Directional 1900 Mhz Square Patch Ring Slot Microstrip Antenna For Wcdma," JEEMECS (Journal Electr. Eng. Mechatron. Comput. Sci., 2019.

[10] D. I. Pratiwi, M. Rivai, and F. Budiman, "Rancang Bangun Deteksi Jalur Pipa Terpendam Menggunakan Mobile Robot dengan Metal Detector," J. Tek. ITS, 2017.

[11] I. Mujahidin, S. H. Pramono, and A. Muslim, " $5.5 \mathrm{Ghz}$ Directional Antenna with 90 Degree Phase Difference Output," 2019.

[12] M. Octavian, Ari; Darmawan, Hofman; Nurohmah, Hidayatul; Ali, "Optimasi Dual Axis Tracking Untuk Photovoltaic Berbasis Firefly Algorithm dan Ant Colony Optimization," SinarFe7, 2018. 
[13] F. Zahro Aska, D. Satria, and W. Kasoep, "Implementasi Radio Frequency Identification (RFID) Sebagai Otomasi Pada Smart Home," Fak. Teknol. Inf. Univ. Andalas, 2012.

\section{Daftar Riwayat Hidup}

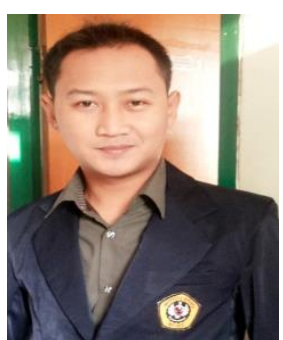

Joko Lasmono, lahir di Kediri 10 september 1989, agama Islam. Penulis menamatkan pendidikan di SDN 56 candi, sidoarjo 2001. Setelah itu Penulis melanjutkan pada jenjang pendidikan SLTP di SMPN 2 candi, sidoarjo dan lulus tahun 2004. Pada tahun 2007 menamatkan pendidikan di SMKN 1 Sidoarjo. Atas anugerah ALLAH SWT maka penulis dapat melanjutkan pendidikan S1 pada Jurusan Teknik Elektro Uninversitas Merdeka Malang hingga saat ini. 